\title{
NUEVAS REALIDADES: INVESTIGACIÓN EN EL MARCO DE LA PANDEMIA
}

\section{[EN] NEW REALITIES: RESEARCH IN THE CONTEXT OF THE PANDEMIC}

Comprometidos como organización a la vanguardia de la educación decalidad paranuestramatrículay colegas internacionales, hoy nos complace la publicación del octavo volumen de nuestra revista Voces desde el Trabajo Social. De forma coherente y sistemática hemos reiterado nuestro accionar guiado por el Código de Ética (2017), el cual matiza nuestro camino profesional vinculado al conocimiento. Hoy la publicación de nuestra revista confirma que asumimos este compromiso con calidad en sus procesos de edición, por lo que es importante reconocer la historia del trabajo de la Junta Editorial de nuestro Colegio.

En el contexto de nuevas formas de relacionarnos frente a una pandemia mundial, nos unimos a divulgar el conocimiento de forma digital para que pueda llegar a diferentes espacios geopolíticos donde la profesión del Trabajo Social lucha junto con los sectores más vulnerados y como parte de la clase trabajadora en sí misma, por la justicia social y la equidad en el acceso a los derechos humanos. De igual forma, problematizamos las estrategias digitales como posibles obstáculos o retos que pueden incidir en la desarticulación de la dimensión humana en los procesos organizativos en dirección de un proyecto ético-político que asumimos como organización. Esta nueva normativa, nos invita y exige comenzar a estudiar y profundizar sobre el impacto de estas nuevas lógicas de actuación en la profesión del Trabajo Social, su ética y naturaleza social, para 
comenzar a construir respuestas fundamentadas en conocimientos. Según Feliciano (2019), considerando un análisis de la definición global de organizaciones internacionales, en estos tiempos se "demanda de un Trabajo Social dirigido hacia una concienciación crítica de la realidad" (p. 33). Esta "nueva" realidad de la distancia física y la era de pura digitalización y tecnología no debe ser acogida de forma liviana, sin cuestionamientos, debates y consensos que a través de la divulgación se pueden visibilizar.

Estas son oportunidades de nuevas líneas de investigación que también deben inquietarnos y provocar investigaciones y pesquisas destinadas a conocer qué ocurre con estas transformaciones en la educación de nuestra niñez, juventud y grupos universitarios. ¿Cuál será el impacto en la educación pública en nuestros países? ¿Cuál es el camino luego de la unión de la política neoliberal con las estrategias virtuales y de distancia física? ¿Cómo los derechos sociales quedan frente al trastoque de este nuevo orden social? Los derechos humanos, su defensa y exigibilidad, siguen en el eje de nuestra actuación profesional y académica, debemos comenzar a tener discusiones profundas sobre todas las ideas que recojo en este mensaje, con el agravante del agobio de una profesión que lucha por ser reconocida como una esencial frente a la debacle de los servicios sociales y las políticas de protección social de nuestros derechos humanos.

La función de la investigación en nuestra profesión sigue como respuesta a miles de interrogantes que surgen del dinámico entramado y complejidad social con la que actuamos desde los diversos escenarios donde se inserta la profesión del Trabajo Social. Comencé reiterando la función de nuestro colectivo profesional en este panorama, el cual ha fortalecido las formas y estrategias de divulgar el trabajo de profesionales del Trabajo Social nacional e internacionalmente para aportar al entendimiento y criticidad que se requiere en la actualidad. O sea, la función de las organizaciones 
profesionales como entes de divulgar la información para fortalecer la práctica académica y profesional, sigue junto a la investigación las respuestas para muchas personas que comprendemos $y$ creemos en la organización y colectivo.

Les invitamos a seguir nuestras publicaciones y a indagar desde la investigación los matices de la pandemia, como evento que impacta la salud pública de nuestros países, pero que requiere respuestas socio-salubristas que no invisibilicen a las poblaciones vulneradas y a la profesión del Trabajo Social como una esencial.

Mabel T. López-Ortiz ${ }^{1}$ Presidenta del CPTSPR

\section{Referencias}

Colegio de Profesionales del Trabajo Social de Puerto Rico. (2017). Código de Ética. Colegio de Profesionales del Trabajo Social de Puerto Rico.

Feliciano, I. (2019). Hacia una práctica transformadora en

Trabajo Social: Implicaciones para la defensa de los derechos humanos y sociales. BiblioGráficas. 